\title{
A Review on FEA and Optimization of Backhoe Attachment in Hydraulic Excavator
}

\author{
Bhaveshkumar P. Patel and J. M. Prajapati
}

\begin{abstract}
Excavators are used primarily to excavate below the natural surface of the ground on which the machine rests and load it into trucks or tractor. Due to severe working conditions, excavator parts are subjected to high loads. The excavator mechanism must work reliably under unpredictable working conditions. Thus it is very much necessary for the designers to provide not only a equipment of maximum reliability but also of minimum weight and cost, keeping design safe under all loading conditions. It can be concluded that, force analysis and strength analysis is an important step in the design of excavator parts. Finite Element Analysis (FEA) is the most powerful technique in strength calculations of the structures working under known load and boundary conditions. In general, computer aided drawing model of the parts to be analyzed must be prepared prior to the FEA. It is also possible to reduce the weight of the mechanism by performing optimization task in FEA. This paper provides the platform to understand the Modeling, FEA and optimization of backhoe excavator attachment, which was already carried out by other researchers for their related applications and it can be helpful for development of new excavator attachment.
\end{abstract}

Index Terms- Backhoe, Excavator, FEA, Optimization

\section{INTRODUCTION}

In the era of globalization and tough competition the use of machines is increasing for the earth moving works, considerable attention has been focused on designing of the earth moving equipments [1]. Today hydraulic excavators are widely used in construction, mining, excavation, and forestry applications [2]. Hydraulic excavators also called diggers. There are many variations in hydraulic excavators. They may be either crawler or rubber-tire-carrier-mounted, and there are many different operating attachments. With the options in types, attachments, and sizes of machines, there are differences in appropriate applications and therefore variations in economical advantages [3]. Excavator digs, elevates, swings and dumps material by the action of its mechanism, which consists of boom, arm, bucket and hydraulic cylinders. Bucket is used for trenching, in the placement of pipe and other under-ground utilities, digging basements or water retention ponds, maintaining slopes and mass excavation. Due to severe working conditions, excavator parts are subject to corrosive effects and high loads.

Manuscript received on March 23, 2011, revised August 22, 2011.

Bhaveshkumar P. Patel is with U. V. Patel College of Engineering in Mechanical Engineering Department, Ganpat University, Kherva-382711, Dist. Mehsana, Gujarat, India, (e-mail:bppmech@gmail.com).

Dr. J. M. Prajapati is with M. S. University (Faculty of Technology and Engineering), Vadodara-390002, Gujarat, India (e-mail: drjmprajapati@gmail.com).
The excavator mechanism must work reliably under unpredictable working conditions [4].

\section{PROBLEM FORMULATION}

Due to severe working conditions, excavator parts are subject to corrosive effects and high loads [3]. The excavator mechanism must work reliably under unpredictable working conditions. Poor strength properties of the excavator parts like boom, arm and bucket limit the life expectancy of the excavator. Therefore, excavator parts must be strong enough to cope with caustic working conditions of the excavator [4]. The skilled operator also cannot know about the terrain condition, soil parameters, and the soil-tool interaction forces exerted during excavation operation are required to find because these forces helpful for better design of the tool, backhoe parts and for trajectory planning [2]. Normally the exactor is working under cyclic motion during excavation process. Due to this repetitive nature of work, cyclic stresses are developed in the parts of backhoe attachment. High level of stresses can cause the damage of critical parts of excavators and it will adversely affected on productivity of machine. Now a day weight is major concern while designing the machine components. So for reducing the overall cost as well as for smoothing the performance of machine, optimization is needed.

\section{UtILITY OF FEA AND OPTIMIZATION FOR BACKHOE ATTACHMENT}

The strength analysis is an important step in the design of excavator parts. Finite Element Analysis (FEA) is the most powerful technique in strength calculations of the structures working under known load and boundary conditions. One can determine the critical loading conditions of the excavator by performing static force analysis of the mechanism involved for different piston displacements. The boundary conditions for strength analysis will be determined according to the results of static force analysis. In general, computer aided drawing (CAD) model of the parts to be analyzed must be prepared prior to the FEA. Preparation of the CAD model can be done either using a commercial FEA program or using a separate commercial program, which is specialized for CAD. Structural optimization for strength is a popular subject in modern engineering design. It has been widely used to obtain an optimum strength/material mass ratio for structures under specified load conditions [4]. The FEA and optimization is versatile tool for designing the backhoe attachment in hydraulic excavator. The next section includes the research work carried out by other researchers in the same field. It can be helpful to the new researchers for reducing the 
failure problems of backhoe components and getting optimized design without compromise with its strength and performance during digging operation.

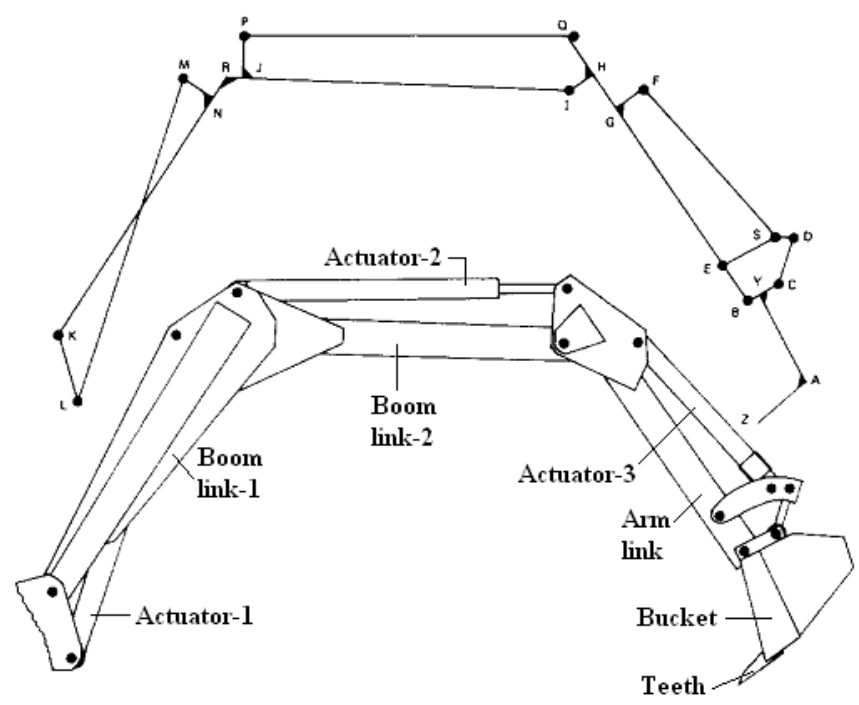

Fig. 1 Structural model of Powerfab 360WT micro- excavator digging arm

\section{FEA OF BACKHOE ATTACHMENT}

Finite element analysis is an important part of the overall design process, serving to verify or validate a design prior to its manufacture. Because finite element analysis is a simulation tool, the actual design is idealized, with the quality of the idealization dependent on the skill and experience of the analyst. Naresh N. Oza, had carried out the FEA and optimization of Earth moving attachment as backhoe in 2006. Accuracy of results is dependent on choice of elements, number of nodes, selection of proper material, boundary conditions, applied loads and expertise of the analyst. Principal steps od Finite Element Analysis are Creation of geometry and its cleanup, specify material and element properties, meshing of geometry in into nodes and elements, apply the loads and boundary conditions, and finally carry out the solution and post processing results. After getting the results, interprets the results and do required corrective steps on it to fulfill the requirement of the problem. They have done the EFA of the boom, arm and bucket by following the standard practice of analysis and carry out the solution for stress and deflection analysis, finally the results are compared with the results obtained from the MathCAD. Optimization for weight is also carried by them and reduces the weight of arm from $180 \mathrm{Kg}$ to $154 \mathrm{Kg}$ and stresses reduced from 386 $\mathrm{MPa}$ to $263 \mathrm{MPa}$. The weight of the bucket is reduced from $165 \mathrm{Kg}$ to $156 \mathrm{Kg}$, and the developed stresses are within the limit [5]. The computational modeling techniques and computer programs developed for the structural design analysis of a microexcavator digging arm mechanism under static or quasi-static loading conditions are outlined by MA Bromfield and WT Evans in 1988. The computer programs allow the design engineer to analyze the forces and stresses at numerous locations on the digging arm, which can assume various geometric configurations. The computer theory was used to develop an integrated CAD software package to allow the design engineer to carry out structural analysis and design optimization calculations on the Powerfab 360WT microexcavator which is shown in figure 1. Product development times and costs have been reduced as a result of using the CAD software. The results showed good correlation between theoretical and experimental stresses, considering the many simplifications that were made in the modelling technique. But to integrate the hydraulic system and structure for optimum performance was not taken for study. The computer modelling technique has been developed for static or quasi-static loading situations but it could be extended to the dynamic situation by introducing mass, inertia, and acceleration terms [6]. Ram Vadhe and Vrajesh Dave, in 1993 have developed a multi-body model of an excavator and to simulate the prototype testing conditions. Multi-body simulation involves the simulation of rigid body system under the application of cylinder forces and/or motions. The link to be designed is considered as a flexible body. Two cycles of digging and dumping operations are simulated to determine the reaction forces generated at each joint and stresses generated on the flexible body. The figure 2 shows stresses in boom of $20 \mathrm{~T}$ excavator at worst position. The generated load case can be used for detailed FE analysis. The stress results of particular gauge locations are also compared with experimental data. They have concluded that the desktop prototype testing helps the designer to find out the worst operating condition, severe conditions and locate the trajectory of operation [7]. Jun-Yong Park, Heui-Won Kim and Wan-Suk Yoo, in 2004, have presented a three dimensional modeling and simulation of a hydraulic excavator using flexible multibody dynamics code ADAMS. A hydraulic excavator consists of 16 bodies, three revolute joints, six spherical joints, four translational joints, eight universal joints and a fixed joint.

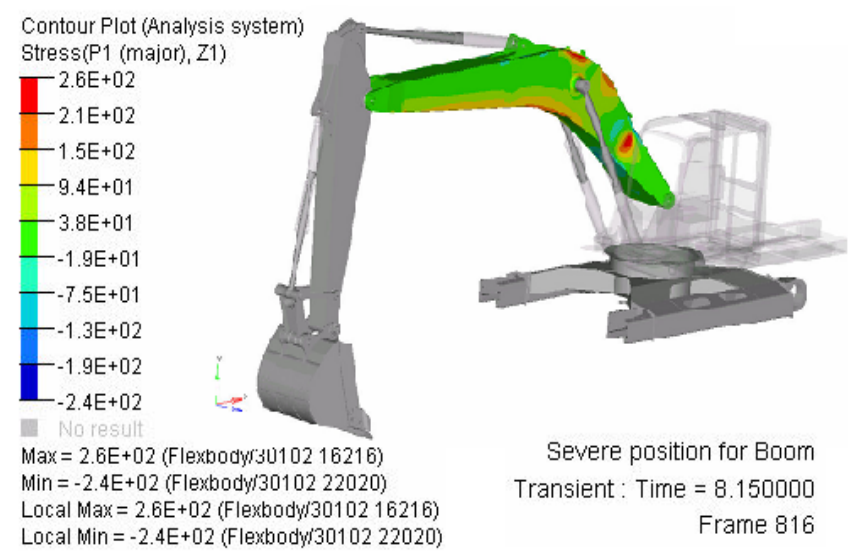

Fig. 2 Stresses in boom at worst position

The boom was modeled as a flexible body using the NASTRAN program and the joint reaction forces of a rigid model and a flexible model are compared. A finite element model of the boom, shown in Figure 3, consists of 4,880 nodes and 4,101 elements (Hex element 1128, Wedge element 364, Quad element 2601, Tri element 8). External nodes are selected at the points at which kinematic joints are located. The flexible effect of the boom on the joint reaction forces was investigated including deformation modes of the boom in the simulation. The accelerations of an arm from the 
ADAMS simulation and the experiment are also compared. The result of the flexible multibody dynamics analysis showed that the operating frequencies were about $4 \sim 5 \mathrm{~Hz}$. For the good result of the flexible multibody dynamics analysis using the ADAMS, it is necessary to set up the step size up small. The calculated results were also compared to the physical experiment. The calculated results were in a good agreement to the experimental results and were acceptable for the design purpose [8]. Yefei Li, Xianghong $\mathrm{Xu}$ and Qinying Qiu, in 2006, have presented an application of Grid-enabled computing technologies in the field of engineering design using Finite Element Method (FEM). A Grid-enabled analysis environment with self-developed codes provides easy access to computational and database capabilities to enhance the engineering system based on FEM results. The aim is to obtain better lighter and cheaper designs by using Finite Element Method based computational analysis models with easy-to-use grid environment. Data structure provides a high level abstraction to heterogeneous data involved in a FEM-based analysis process. Various search algorithms exposed in this environment enable complex search strategies to be constructed within the environment [9]. Tadeusz Smolnicki, Damian Derlukiewicz, and Mariusz Stańco, in 2008, have represented an application of the finite element method and accurate representation of the rigidity of support elements, mounting bolts, and phenomena occurring in the raceway-rolling element-raceway assembly of a caterpillar excavator, allowed for identification of the load distribution onto the individual rolling elements of the bearing. The results were compared with the classical compound model (iterative solution), however not taking into account deformation of the support elements under load. The results were then presented in figure 4 in the form of a plot. It was concluded that there is a significant discrepancy in not only the load distribution but also in the maximum load values. For the upper track the differences reach $70 \%$, and for the lower track $25 \%$. The evaluated bearing, selected according to the guidelines of one of the largest manufacturers of slewing bearings, for an existing single-bucket excavator, is subject to very high loads, even when fulfilling the allowable mount surface flexure parameters required by the manufacturer for this bearing [10].

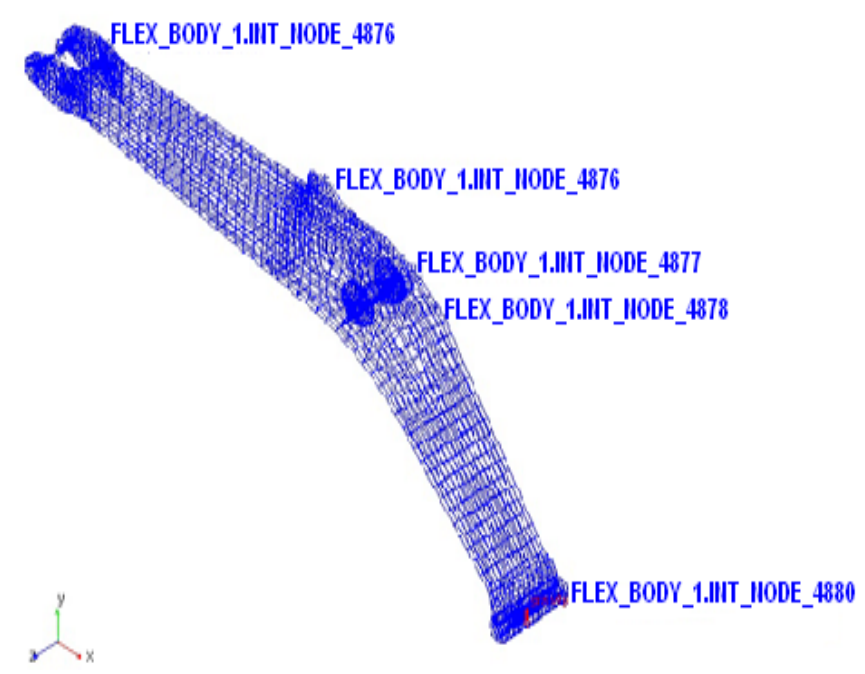

Fig. 3 The Finite Element model of the boom
Luigi Solazzi, in 2010, have carried out study on the boom and the arm of an excavator in order to replace the material, which they are usually made of, with another material. In particular, the study wants to substitute the steel alloy for an aluminium alloy. This change lightens the components of the arm, allows to increase the load capacity of the bucket and so it is possible to increase the excavator productivity per hour. Figure 5 shows the stress state. It has been assumed that the material used to make the arm is the steel alloy S355 JO EN 10025.

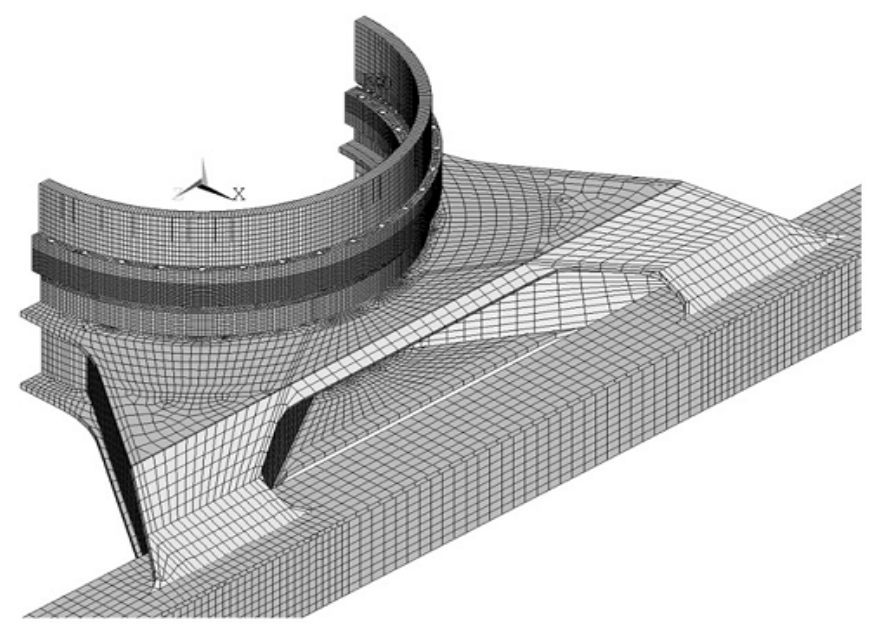

Fig. 4 Digital model — finite element grid (1/2 of the model)

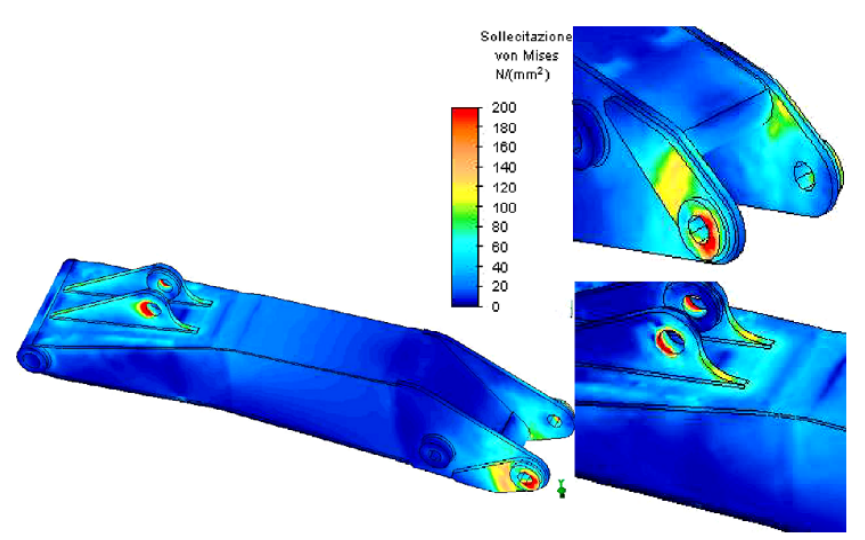

Fig. 5 Stress state (Von Mises) in the first element

The evaluation of the new geometry of the arm with the different material has been studied in order to obtain at least the same safety factor and deformability of the original geometry (steel alloy) and for the new geometry (aluminium alloy). On the basis of the relationships state above between the geometry of the steel alloy panel and the geometry of the aluminium alloy panel, for each component of the arm has been developed a new cross-section. With this cross-sections it has been numerically modeled the whole element of the arm.

The consequent step is to perform the FEM analyses in order to verify both the safety factor and the flexibility of the component as regards to the original value. This last operation has been repeated iteratively until the goal has been achieved.

Based on this study they achieve that the total weight of the arm is reduced of about $50 \%$ and the capacity of the bucket increased of about $30 \%$. Also increase the capacity of the bucket from $1 \mathrm{~m}^{3}$ to $1.35 \mathrm{~m}^{3}$ and so to increase the 
productivity per hour of the excavator [11].

\section{OPTIMIZATION OF BACKHOE ATTACHMENT}

J. Mottl has described 'Voting Method' for optimization of the weight of an excavator in 1992. He has carried out optimization for all parts of the excavator such as the chassis, cabin, jib, etc. with consideration as non-linear programming problem [12]. Mehmet Yener, in 2005, Parameterization of boom geometry is done to add some flexibility to interface called OPTIBOOM. Optimization of boom carried out for HMK 220LC model excavator.

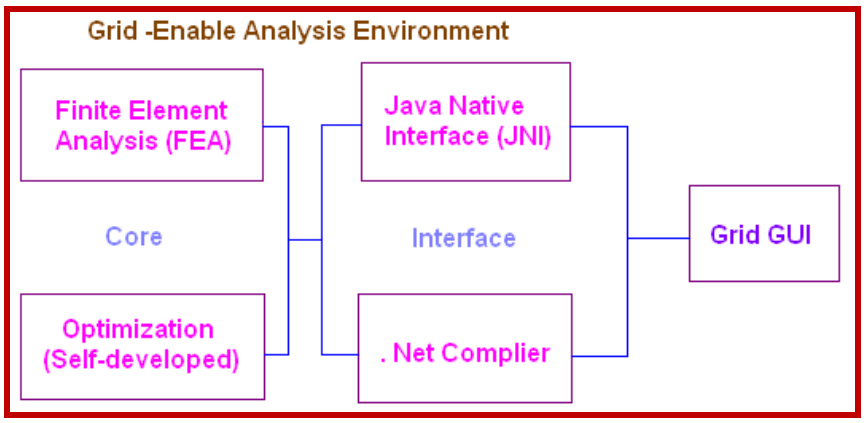

Fig. 6 Grid-enable analysis environment

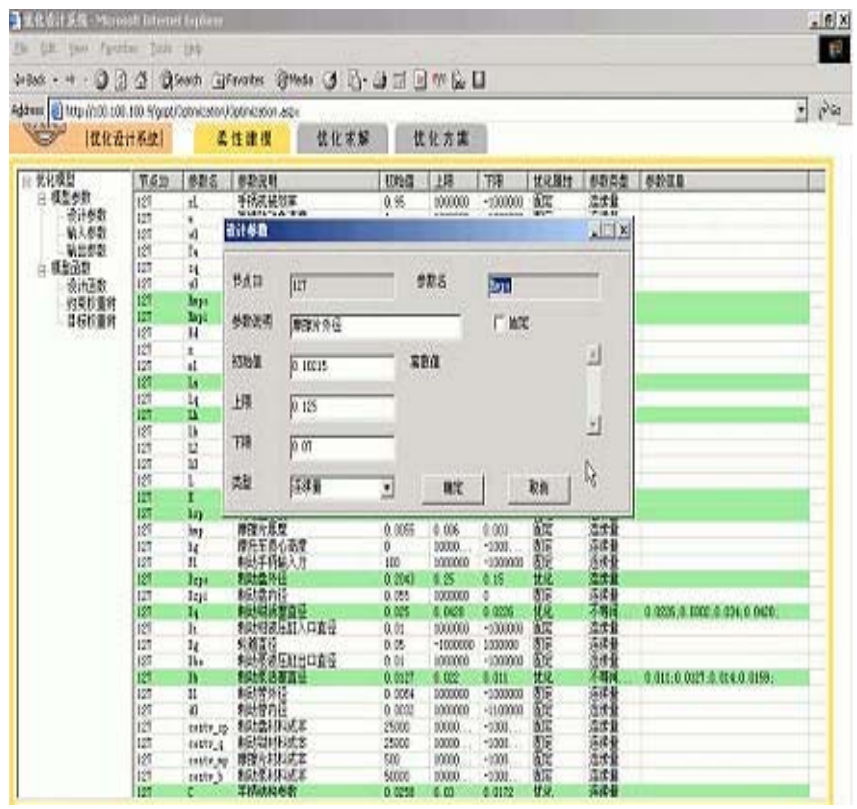

Fig. 7 Results of optimization

In general there are 3 types of structural optimization techniques: sizing, geometrical and topology optimization. Out of these three techniques, topology optimization may give better results by changing the initial topology. Starting from an initial design, more than 100 alternative designs were created and compared with each other in terms of boom mass and maximum von Mises stresses. 21 shape parameters have been changed to obtain new boom geometries and the best design has been found at $90^{\text {th }}$ design alternative. Maximum von Mises stress value at the $90^{\text {th }}$ boom is $146 \mathrm{MPa}$ while it is $186 \mathrm{MPa}$ in the initial boom shape. Maximum von Mises stress has been reduced by $21.5 \%$. Mass of the $90^{\text {th }}$ model is $1454 \mathrm{Kg}$ and mass of the initial boom is $1403 \mathrm{~kg}$. thus, mass of the boom increases only by $3.6 \%$ [4]. Yefei Li, Xianghong Xu and Qinying Qiu, in 2006, have described a Grid-enabled analysis with self-developed codes provides easy access to computational and database capabilities to enhance the engineering system based on FEM results which is shown in figure 6 . The aim is to obtain better lighter and cheaper designs by using Finite Element Method based computational analysis models with easy-to-use grid environment. Data structure provides a high level abstraction to heterogeneous data involved in a FEM-based analysis process. Various search algorithms exposed in this environment enable complex search strategies to be constructed within the environment. They have explained a strategy of combining a design of expert system platform and at genetic algorithm (GA) with gradient descent search is used on design and checking of the hydraulic excavator. Optimization is carried out using genetic algorithm followed by a local search on the best point found using the Lagrange interval search method from self-developed codes. The results then used to build CAD model for validating the stress and displace distribution of the whole parts of working equipment using the ANSYS model. It shows that the maximum stress of the working equipment is still under safe state, and results of optimization is as shown in figure 7 , thus the structure design object has to been made compromise. As we know, a typical Finite Element Analysis (FEA) problem is composed by three essential steps: Modeling, mesh generation and solution, and post-process. A parametric geometry model suitable for FEM analysis is first generated using CAD software Pro/Engineer. The subsequent mesh is generated with minimum reference to the geometry information, as only the top-level entities in the CAD model are referenced in the meshing. There are two typically mesh tools used, either direct access provided to CAD parts and assemblies in their native mode, or third-party standard exchange data formats used. They have utilized interface between them which produce ANF file format as exchange geometry. Generation is processed in ANSYS batch mode. Volume mesh is then generated by applying parameters on adaptive meshing. The structure FEA solver ANSYS is then used to solve the problem, the model used in this work is an assembly static analysis. A three dimensional working equipment optimization problem is presented here. The problem is both complex and has a high computational cost. The goal is to reduce the weight and manufacture cost of hydraulic excavator, FEM is adopted here to analysis the whole structure's stress and displacement distribution [9].

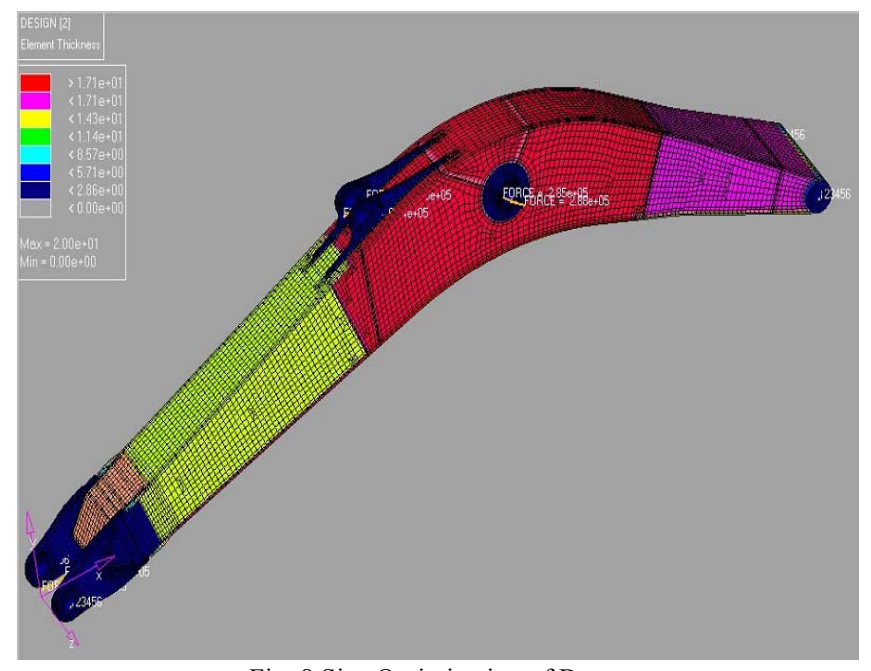

Fig. 8 Size Optimization of Boom 


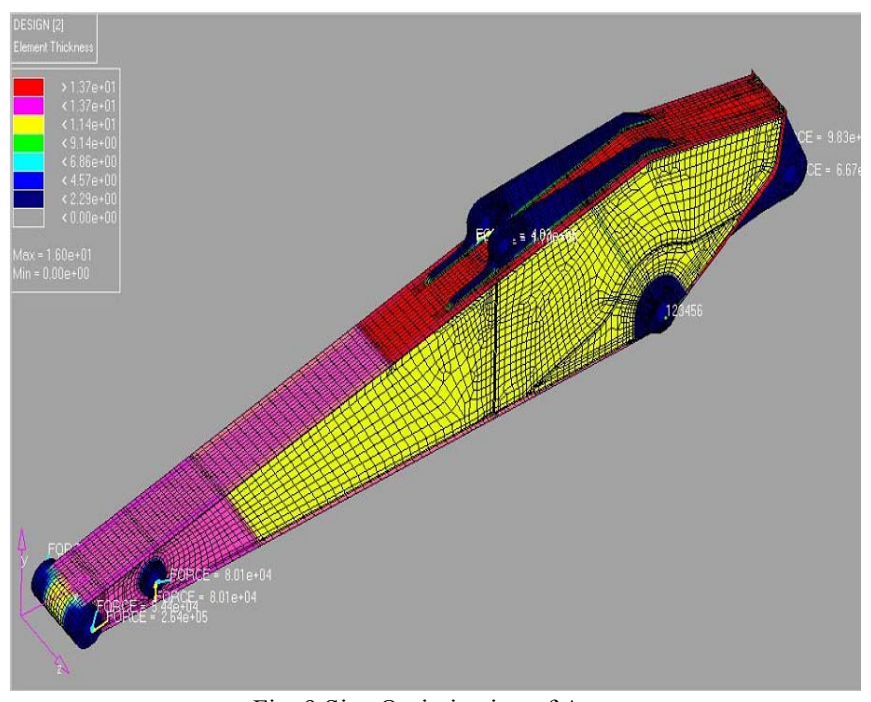

Fig. 9 Size Optimization of Arm

Bipin N. Patel, in 2007, have carried out study for optimization of backhoe attachment components like boom and arm for the purpose of reduction in weight. He has done the modeling using CATIA software, meshing in Hypermesh software, analysis in Abaqus software, and post processing in I-deas software. Optimization of boom is doing in Optistruct software. Optimum boom and arm geometry is shown in figure 8 and figure 9 respectively. After performing the optimization task, the weight of the boom is reduced up to 95 $\mathrm{Kg}$. Same way optimization is done for arm and result shows the $40 \mathrm{Kg}$ reduction in weight of the arm, without increasing the stress level compare to previous geometry of the arm and boom [13]. Cevdet Can Uzer, in 2008, have utilized the OPTIBOOM software developed by Mehmet Yener in 2005, which generates a CAD model using a finite set of parameters and then performs a finite element analysis by using a modified commercial program. The model parameter generation, model creation, analysis data collection and data evaluation phases are done by the Python and Delphi based computer codes. A global heuristic search strategy such as genetic algorithm is chosen to search different boom models and select an optimum. Evolutionary structural optimization method is used for removing inefficient material from the structure by using the predefined criteria. Optimum solutions of boom of HMK360 LC excavator is carried out. Initial design of the boom was $5 \%$ heavier than the final design and maximum stress was $10 \%$ higher than the Von Mises design stress criterion as shown in figure 10. Maximum stress was limited by predetermined global maximum stress value and weight is decreased $4.6 \%$ of the initial design. Actually obtained result is not the best one but it is one of the good results which is satisfying design criteria and aimed mass [14].

Feng Suli, Tian zhigang, Zhai Xuhua, Zhang Guangyu and Li Yan, in 2008, optimization mathematical model is established, where the mass is defined as objective function and the performance is taken as constraints condition as follows.

$$
X=\left[x_{1}, x_{2}, x_{a}, x_{4}\right]
$$

where, $\mathrm{x}_{1}, \mathrm{x}_{2}$ are width and thickness of the flat steel (m), $\mathrm{x}_{3}$, $\mathrm{x}_{4}$ are length and thickness of hollow square steel (m).

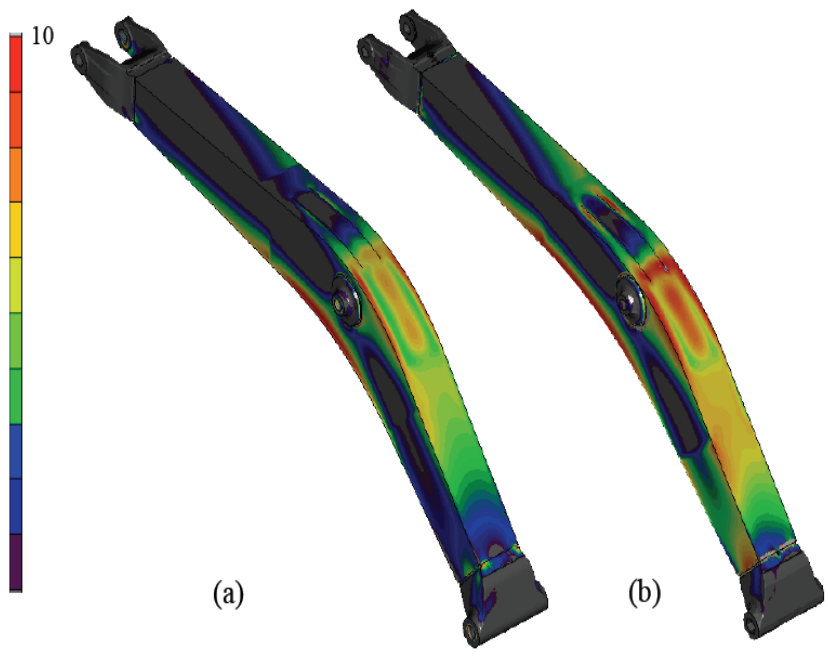

Fig. 10 Isometric view of the boom models representing stress distribution over the upper plates. (a) Initial model. (b) Optimized model.

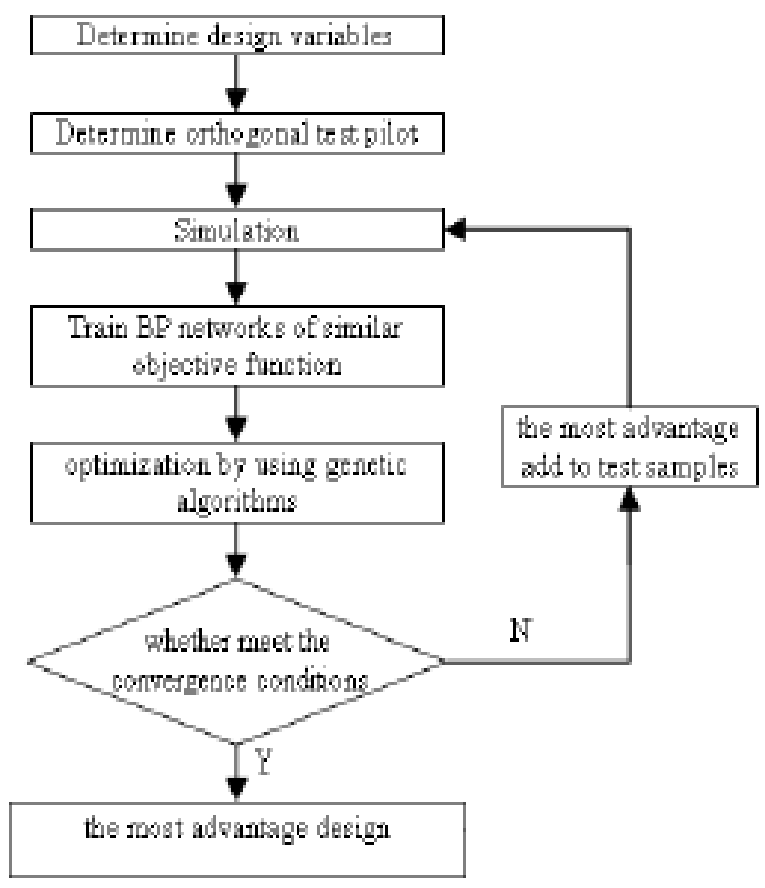

Fig. 11 Optimized design flow chart based on neural network and genetic algorithms of top guard for excavator

Here, the mass of the top guard as objective function, namely:

$$
\min f(x)=\rho\left[p l_{1} x_{1} x_{2}+4 q l_{2}\left(x_{g} x_{4}-x_{4}^{2}\right)\right]
$$

where, $\rho$ is density of the material, $p$ and $q$ are the quantity of flat steel and hollow square steel, respectively, and $l_{1}$ and $l_{2}$ are length of flat steel and hollow square steel, respectively.

There are three constraints considered here as follows:

(1) Deformation constraint

$$
g_{1}(x)=\Delta_{\min }-\Delta \leq 0
$$

where, $\Delta$ is the largest deformation of top guard and $\Delta_{\min }$ is the allow deformation of top guard.

(2) Strength and strain constraints

$$
\begin{aligned}
& \vartheta_{2}(X)=\sigma-[\sigma] \leq 0 \\
& \vartheta_{3}(X)=\varepsilon-[\varepsilon] \leq 0
\end{aligned}
$$


where, $\sigma$ and $\varepsilon$ are the max. stress and strain of top guard, respectively, $[\sigma]$ and $[\varepsilon]$ are the allow stress and strain of the top guard's material.

(3) Boundary constraints

$$
\begin{aligned}
& \vartheta_{3+i}(x)=x_{i}-x_{i} \leq 0 \\
& 9_{p+i}(x)=x_{i 2}-x_{i} \leq 0 \quad i=1,2,3,4
\end{aligned}
$$

where, $x_{i l}$ and $x_{i u}$ are the lower limit and upper lilitof design variables.

In order to transform the optimization problems into unconstrained problem an new target function is constituted as follows;

$$
f_{\text {TaW }}(x)=f(x)+R \sum_{j=1}^{p} d_{i}
$$

where, $\mathrm{R}$ is punishment coefficient, a very large positive number, $d_{i}$ denotes state of the ith inemass constraint where:

$$
f(x)= \begin{cases}0, & g_{i}(X) \leq 0 \\ 1_{s} & g_{i}(X)>0\end{cases}
$$

The relationship between the new objective function and the design variables is very complicated; thus computational simulation is employed using neural genetic algorithm. The steps of optimized design in the form of flow chart based on neural network and genetic algorithm of top guard for excavator is shown in figure 11.

Because of the material non-linearity, geometry non-linearity and contact non-linearity between the design variables and performance, explicit expression is hard to establish. And all the design programs require a large amount of calculation for finite element analysis owing to non-linear, large deformation. In order to solve this problem, the optimization method based on neural network and genetic algorithm is put forward, which calculates the response of protection structure through selecting sample points, trains neural network to simulate the relations between design variables and performance, and utilizes the genetic algorithm to solve the global optimal point. A genetic algorithm method was used to optimize the design of the top guard of excavator by developing computational program and optimization program as shown in figure 11. The optimization results are: $\mathrm{x}_{1}=0.02, \mathrm{x}_{2}=$ $0.003, x_{3}=0.04$ and $x_{4}=0.0012$. The mass of this structure is $\mathrm{m}=18.175 \mathrm{Kg}$, the mass of the original structure is $\mathrm{m}=$ $34.883 \mathrm{Kg}$. It means there is $47.8 \%$ mass reduced from the original mass of the structure [15] .

\section{CONCLUSION}

The FEA and optimization is versatile tool for designing the backhoe attachment in hydraulic excavator. To carry out the modeling and FE analysis of an excavator, various software used by researchers like PRO-ENGINEER, ADAMS, NASTRAN, CATIA, ANSYS, Hypermesh, Abaqus, I-deas etc. according to their ease of user friendliness and accuracy of results. By conducting FEA it is very easy to identify weak components through strength analysis of excavator attachment and corrections are possible in early stage of design. OPTIBOOM software developed by Mehmet Yener in 2005 and optimization of boom carried out by him. OPTIBOOM software utilized by Cevdet Can Uzer, in 2008 with modified commercial program, which generates a CAD model using a finite set of parameters and then performs a finite element analysis. A Grid-enabled analysis with self-developed codes provides easy access to computational and database capabilities to enhance the engineering system based on FEM results. Topology optimization may give better results by changing the initial topology. Genetic algorithm (GA) and neural network is a powerful tool for optimization. Better lighter and cheaper designs can be obtained by using Finite Element Method and optimization techniques.

\section{REFERENCES}

[1] Mehta Gaurav K, "Design and Development of an Excavator Attachment" M. tech Dissertation Thesis, Nirma University, Institute of Technology, Ahmedabad, May 2008, pp. 1.

[2] Bhaveshkumar P. Patel, Dr. J. M. Prajapati, "Soil-Tool Interaction as a Review for Digging Operation of Mini Hydraulic Excavator", International Journal of Engineering Science and Technology, Vol. 3 No. 2, February 2011, 894-901.

[3] Bhargav J Gadhvi, B. P. Patel and P. M. Patel, "Development of a Controller for Mini Hydraulic Excavator as a Review", Proceeding of National Conference on Recent Advances in Manufacturing, SVNIT, Surat, 19th - 21st July, 2010, pp. 198-203.

[4] Mehmet Yener, "Design of a Computer Interface for Automatic Finite Element Analysis of an Excavator Boom", M.S. Thesis, The Graduate School of natural and Applied Sciences of Middle East Technical University, May 2005, pp. 1-4, 68-69.

[5] Nareshkumar N. Oza, "Finite Element Analysis and Optimization of an Earthmoving Equipment Attachment - Backhoe", M. tech Dissertation Thesis, Nirma University, Institute of Technology, Ahmedabad, May 2006, pp. 31-68.

[6] MA Bromfield and WT Evans, "Computer modelling of microexcavator", Computer Aided Design, Butterworth \& Co (Publishers) Ltd., Vol. 20, No. 9, November 1988, pp. 549-554.

[7] Ram Vadhe and Vrajesh Dave, " Multi-Body Simulation of Earthmoving Equipment using Motionview/Motionsolve”, Driving Innovations with Enterprise Simulation, L \& T e-engineering Solutions, 1993, pp. 1-5.

[8] Jun-Yong Park, Heui-Won Kim and Wan-Suk Yoo, "Matching of Flexible Multibody Dynamic Simulation and Experiment of a Hydraulic Excavator", Proceedings of ACMD, 2004, pp. 459-463.

[9] Yefei Li, Xianghong Xu and Qinying Qiu, "FEM-Based Structure Optimization with Grid-Enabled Analysis Environment", Proceedings of the 6th World Congress on Intelligent Control and Automation, IEEE, Dalian, China June 21 - 23, 2006, pp. 6915-6919.

[10] Tadeusz Smolnicki, Damian Derlukiewicz, and Mariusz Stańco, "Evaluation of load distribution in the superstructure rotation joint of single-bucket caterpillar excavators", Automation in Construction, Elsevier, 2008, pp. 218-223.

[11] Luigi Solazzi, "Design of aluminium boom and arm for an excavator", Journal of Terramechanics, Elsevier, Vol. 47, 2010, pp. 201-207.

[12] J. Mottl, "Excavator optimization using the voting method", Computer Methods in Applied Mechanics and Engineering, No. 98, North-Holland, 1992, pp. 227-250.

[13] Bipin N. Patel, "Finite Element Analysis and Optimization of Arm and Boom of Excavator", M. Tech. Thesis, Institute of Technology, Nirma University of Science and Technology, Ahmedabad, May 2007, pp. 40-72.

[14] Cevdet Can Uzer, "Shape Optimization of an Excavator Boom by Using Genetic Algorithm”, Master of Science Dissertation Thesis, The Graduate School of Natural and Applied Sciences of Middle East Technical University, June 2008, pp. iv, 25, 90, 104.

[15] Feng Suli, Tian zhigang, Zhai Xuhua, Zhang Guangyu and Li Yan, "Optimization of the Top Guard for Excavator Based on Neural Genetic Algorithm”, International Conference on Intelligent Computation Technology and Automation, IEEE, 2008, pp. 1240-1243. 


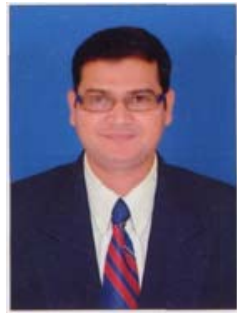

Bhaveshkumar P. Patel born in small village Kukadia situated in Sabarkantha district of Gujarat State, India dated on $10^{\text {th }}$ April 1977. He has completed his graduation in Mechanical Engineering from S. V. National Institute of Technology, Surat, Gujarat, India in the year 2002 and post graduation (ME) with specialization in CAD/CAM from L. D. College of Engineering, Ahmedabad, Gujarat, India in the year of 2006 with good academic record.

He has industrial experience more than six years and seven year experience in the field of academic. He is presently working as an Assistant Professor in Mechanical Engineering Department of U. V. Patel College of Engineering, Ganpat University, Kherva, Dist. Mehsana, Gujarat, India. He has guided $9 \mathrm{M}$. Tech students in their dissertation. There are nine research papers published in various referred International Journals in the field of design and dynamics. There are 30 research papers presented in National and International conferences and published in their proceedings.

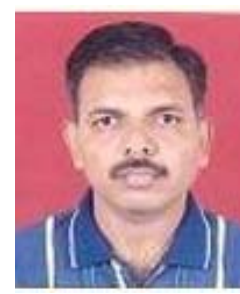

Dr. J. M. Prajapati born in 1973, Telavi village of Ahmedabad district, Gujarat state, India. He has completed his graduation in Mechanical Engineering and post graduation (ME) with specialization in Machine Design from S. P. University, V. V. Nagar, Gujarat, India in the year 1995 and 2003 respectively. He has successfully completed his $\mathrm{Ph}$. D. from Hemchandracharya North Gujarat University, Patan, Gujarat, India in the year of 2009 in the field of Robotics with excellent academic profile.

He has industrial experience more than two years and twenty three year experience in the field of academic. He is presently working as an Associate Professor in the Faculty of Technology and Engineering, The M. S. University of Baroda, Vadodara. Gujarat, India. He has guided three M. Tech dissertation. There are 12 research papers published in various referred International Journals in the field of machine design and robotics. There are total 9 research papers presented and published in National and International conferences. There are six Ph.D. scholars are doing their research work under his guidelines. There are many expert lectures delivered in the area of design optimization and robotics at various well established Institutions in India. 